\title{
Mycoplasma pulmonis Infections Cause Long-lasting Potentiation of Neurogenic Inflammation in the Respiratory Tract of the Rat
}

Donald M. McDonald, ${ }^{*}$ Trenton R. Schoeb, ${ }^{\ddagger}$ and J. Russell Lindsey ${ }^{\ddagger}$

*The Cardiovascular Research Institute and Department of Anatomy, University of California, San Francisco, California 94143; and ${ }^{\ddagger}$ The Birmingham Veterans Administration Medical Center and Department of Comparative Medicine,

University of Alabama at Birmingham, Birmingham, Alabama 35294

\begin{abstract}
These experiments were done to learn whether Mycoplasma pulmonis infections of the respiratory tract of rats can potentiate "neurogenic inflammation" and whether this potentiation is amplified by factors that exacerbate the infections. Pathogen-free F344 rats were inoculated intranasally with $M$. pulmonis or with sterile culture medium and then lived for 4 wk in an ammonia-free atmosphere or in air containing ammonia (100 parts per million). Neurogenic inflammation was evoked by an intravenous injection of capsaicin, and $5 \mathrm{~min}$ later the magnitude of the response was quantified by measuring the amount of extravasation of two tracers, Monastral blue pigment and Evans blue dye. We found that vascular permeability in the tracheas of all rats was normal in the absence of capsaicin. However, a $75-\mu \mathrm{g} / \mathrm{kg}$ dose of capsaicin, which caused almost no extravasation of Evans blue in the tracheas of pathogen-free controls $(17 \pm 3 \mathrm{ng} / \mathrm{mg}$; mean $\pm \mathrm{SE})$, produced extensive extravasation in the infected rats $(135 \pm 18 \mathrm{ng} / \mathrm{mg} ; P<0.001)$. Similarly, this dose of capsaicin produced 30 times as much Monastral blue extravasation in the infected rats (area density $=47 \pm 8 \%$ of surface area) as it did in the pathogen-free rats (1.6 $\pm 0.5 \% ; P<0.001)$, a difference that resulted from increases in the number of Monastral blue-labeled postcapillary venules and in the amount of labeling per venule. Exposure of the infected rats to ammonia exacerbated the infections, further increased the number of Monastral blue-labeled vessels and the amount of labeling per vessel, and made the rats so sensitive to capsaicin that a normally tolerable dose of $150 \mu \mathrm{g} / \mathrm{kg}$ i.v. caused fatal apnea. Ammonia did not have these effects in pathogen-free rats. We conclude that $M$. pulmonis infections of the airway mucosa cause a potent, long-lasting potentiation of neurogenic inflammation, which results in part from an increase in the number and responsiveness of mediator-sensitive postcapillary venules. These changes can be amplified by environmental factors such as ammonia which exacerbate the infections. (J. Clin. Invest. 1991. 87:787-799.) Key words: aniogenesis • capsaicin • electron microscopy • plasma extravasation • postcapillary venules $\bullet$ respiratory tract infections $\bullet$ sensory nerves • vascular permeability
\end{abstract}

Address reprint requests to Dr. Donald M. McDonald, Cardiovascular Research Institute, Box 0130, University of California, San Francisco, CA 94143 . 1990

Received for publication 2 May 1990 and in revised form 19 October

J. Clin. Invest.

(C) The American Society for Clinical Investigation, Inc.

$0021-9738 / 91 / 03 / 0787 / 13 \$ 2.00$

Volume 87, March 1991, 787-799

\section{Introduction}

"Neurogenic inflammation" is a type of inflammation mediated by substances released from sensory nerves $(1,2)$. Neurogenic inflammation in the mucosa of the respiratory tract is manifested by vasodilatation, increased vascular permeability with the extravasation of plasma proteins, diffusion of extravasated plasma proteins into the airway lumen, adherence of leukocytes to the vascular endothelium, and secretion of mucus (3-8).

Several factors can change the magnitude of the neurogenic inflammatory response. Transient reductions in the response can be produced by antagonists which block the action of substance $P$, a presumptive mediator of neurogenic inflammation (9), as well as by local anesthetics ( 3 ), $\beta_{2}$-adrenergic agonists ( 5 ), xanthines (5), opioids (10), corticotropin-releasing factor (11), and glucocorticoids $(12,13)$. Alternatively, the neurogenic inflammatory response can be potentiated by inhibitors of neutral endopeptidase (EC 3.4.24.11 or enkephalinase), an enzyme which degrades the peptide mediators that produce neurogenic inflammation (14-16).

Of potential clinical relevance, the magnitude of the neurogenic inflammatory response is altered by viral respiratory tract infections (17-19). For example, experimentally induced parainfluenza virus infections augment the contraction of airway smooth muscle induced by substance $P$ and capsaicin, a sensory nerve stimulant $(17,18)$. The infections also potentiate the increase in vascular permeability evoked by capsaicin (19). These changes coincide with the peak of the viral infections, some 4-6 d after their onset.

Neurogenic inflammation is also potentiated by naturally occurring respiratory tract infections due to a combination of organisms, including parainfluenza type I (Sendai) virus, coronavirus (sialodacryoadenitis virus/rat coronavirus), and $M y$ coplasma pulmonis $(12,20)$. However, because of its extraordinary magnitude and long if not permanent duration, the potentiation produced by these combined infections differs from that produced by transient viral infections.

A first step toward understanding the mechanism of this long-lasting potentiation is determining which of the three organisms is responsible for the change. The protracted nature of the change and the characteristic pathological alterations in the airway mucosa point to the $M$. pulmonis infections $(12,20)$. Nonetheless, as Sendai virus and coronavirus infections can increase the severity of $M$. pulmonis infections $(21,22)$, it is unknown whether $M$. pulmonis infections can augment the neurogenic inflammatory response in the absence of the viral infections.

The present studies had five goals. We sought to determine (a) whether $M$. pulmonis infections can by themselves potentiate neurogenic inflammation in the respiratory tract of rats; 
(b) whether the effects of $M$. pulmonis infections on neurogenic inflammation are amplified by environmental conditions such as exposure to ammonia which makes the infections worse; $(c)$ whether exposure to ammonia potentiates neurogenic inflammation in the absence of $M$. pulmonis infections; $(d)$ whether the potentiation of neurogenic plasma extravasation results in part from an increase in the number of mediator-sensitive blood vessels or from an increase in the responsiveness of individual vessels; and $(e)$, whether the magnitude of the neurogenic inflammatory response corresponds to the severity of the pathological changes produced in the tracheal mucosa by $M$. pulmonis infections.

Our strategy was as follows: Pathogen-free rats were inoculated intranasally with $M$. pulmonis or with sterile culture medium and then lived in isolators for $4 \mathrm{wk}$. Some of the rats were exposed to ammonia during this period to exacerbate the $M$. pulmonis infections (23-25). Thereafter, we determined the magnitude of the neurogenic inflammation evoked in the airways by a standardized dose of capsaicin, a drug known to induce neurogenic inflammation and thereby cause plasma extravasation $(5,20,26-28)$.

The amount of plasma extravasation in the trachea was quantified with two tracers having different properties. Evans blue dye, which binds to albumin, was used to measure the extravasation of plasma proteins (29). Monastral blue pigment, which crosses the endothelium and labels the walls of abnormally permeable blood vessels but is not extravasated from normal tracheal blood vessels $(6,30)$, was used to exclude the possibility that the plasma extravasation was due to hemodynamic changes evoked by the capsaicin (31) rather than to an increase in vascular permeability. This tracer also enabled us to learn whether differences in the amount of plasma extravasation resulted from an increase in the number of mediator-sensitive blood vessels or from an increase in the responsiveness of individual vessels.

The presence of $M$. pulmonis in the airways was confirmed at the end of the experiments by nasal, tracheal, and lung cultures, serological antibody titers, and electron microscopy. The possibility of interference by other respiratory pathogens was excluded by measuring antibody titers to Sendai virus, coronavirus, and six other organisms. In addition, the pathological changes in the tracheal mucosa were correlated with the magnitude of the neurogenic inflammatory response and were compared by light and electron microscopy to those produced by the combined infections studied previously $(12,20)$, with particular attention being paid to the thickness, vascularity, and cellular composition of the tracheal mucosa.

\section{Methods}

M. pulmonis cultures. M. pulmonis of the $5782 \mathrm{C} 4$ strain $(24,32)$ was grown in mycoplasma broth $\mathrm{A}(32)$, harvested in the late log phase of growth, and frozen at $-70^{\circ} \mathrm{C}$ in $1-\mathrm{ml}$ aliquots. Before being used for inoculation, the culture medium was diluted to a concentration of $10^{6.5}$ colony-forming units of $M$. pulmonis per $50 \mu \mathrm{l}$, as determined by quantitative culture.

4 wk after inoculation, selected rats (see below) were anesthetized and homogenates of their nasal passages, tracheas, and lungs were cultured quantitatively for $M$. pulmonis by serial dilution and plating as described previously $(24,32)$.

Initial treatment of animals. 108 male rats from a barrier-maintained breeding colony of gnotobiotic F344 rats at the University of
Alabama were used in three experiments. ${ }^{1}$ Rats 8-12 wk of age were removed from the breeding isolators and housed in separate plastic film isolators for the experiments without jeopardizing their gnotobiotic status.

In the first experiment 25 rats, sedated by an intramuscular injection of Ketamine and Rompun $(0.05 \mathrm{ml}$ of a mixture containing 98.5 $\mathrm{mg} / \mathrm{ml}$ of Ketamine [Parke-Davis, Morris Plains, NJ] and $1.5 \mathrm{mg} / \mathrm{ml} \mathrm{of}$ Rompun [Haver-Lockhart, Shawnee, KS]), were inoculated into each nostril with $25 \mu \mathrm{l}$ of culture medium containing $M$. pulmonis. Each rat received a total dose of $10^{6.5}$ colony-forming units of the organisms. As controls, an additional 18 rats were inoculated with the same volume of sterile culture medium. The rats then lived for $4 \mathrm{wk}$ in isolators in which the atmospheric ammonia concentration never exceeded 1.5 $\mu \mathrm{g} /$ liter ( 2 parts per million) and was usually unmeasurable.

The second experiment was identical to the first with the exception that the M. pulmonis inoculated rats $(n=24)$ were exposed for $4 \mathrm{wk}$ to an atmosphere containing ammonia. A concentration of $76 \mu \mathrm{g} \mathrm{NH}_{3}$ per liter of air ( 100 parts per million) was maintained with gaseous ammonia from a tank of liquid anhydrous $\mathrm{NH}_{3}$ (PB \& S Chemical Co., Henderson, KY), which was dispensed into the middle of the incoming air stream of the exposure chamber $(23,24)$. The concentration of ammonia within the isolators was monitored daily with a Drager Multi Gas Detector (Dragerwerk, Lubeck, FRG). As controls for this experiment, an additional 14 rats were inoculated with sterile medium and then lived in an ammonia-free environment.

In the third experiment, 27 rats were inoculated with sterile culture medium. For the next $4 \mathrm{wk} 15$ of these rats were exposed to ammonia as just described and 12 were exposed to ammonia-free air.

At the end of the 4-wk experiments, quantitative cultures for $M$. pulmonis were prepared from the airways of six infected rats not exposed to ammonia, six infected rats exposed to ammonia, and three pathogen-free controls. The remaining 93 rats were flown to the University of California, San Francisco, in seven groups of 12-15 rats each. The rats were housed in filter-protected containers during shipment and were studied within one day of their arrival in San Francisco. When studied, the pathogen-free controls had an average body weight of $300 \pm 3 \mathrm{~g}(n=41$; mean $\pm \mathrm{SE})$. The infected rats not exposed to ammonia weighed $277 \pm 5 \mathrm{~g}(n=19)$, and the infected rats exposed to ammo-

\footnotetext{
${ }^{1}$ This breeding colony of F344 rats has been maintained since January 1984 by the Department of Comparative Medicine at the University of Alabama at Birmingham. The rats are bred by brother-sister matings and housed in Trexler type plastic film isolators (Germ-Free Supply Division, Standard Safety Equipment Co., Palatine, IL). The initial breeding stock for this colony consisted of one male and two female littermates obtained as axenics from Charles River Breeding Laboratories, Wilmington, MA $\left(\mathrm{CDF}^{\mathrm{R}} / \mathrm{Crl}\right)$. (The original breeders were obtained in 1960 from Dr. Wilhelmina F. Dunning, Papanicolaou Cancer Research Institute, Miami, FL.) The University of Alabama breeding colony is monitored for contamination biannually by fecal cultures. The colony is also screened twice annually by studying selected rats by necropsy and histological examination for pathological lesions and parasites, by culturing for bacterial pathogens including mycoplasmas, and by serologic testing with enzyme-linked immunosorbent assays for the cilia-associated respiratory bacillus (done by Microbiological Associates, Inc., Rockville, MD) and viral pathogens (coronaviruses, Kilham rat virus, mouse adenoviruses 1 and 2, pneumonia virus of mice, reovirus type 3, Sendai virus, and Toolan $\mathrm{H}-1$ virus; assays done by Charles River Professional Services, Wilmington, MA). No murine pathogens have been detected by these procedures. However, an unspeciated, nonpathogenic, microaerophilic, gram-positive bacillus is present in the gastrointestinal tract of the rats in this colony; thus, they are gnotobiotic (pathogen-free), not axenic (germfree). The rats are fed an autoclaved diet formulated for axenic rodents (Prolab 3500 Autoclavable Diet, Agway Inc., Syracuse, NY) and receive autoclaved tap water ad libitum.
} 
nia weighed $234 \pm 5 \mathrm{~g}(n=18)$. The pathogen-free rats exposed to ammonia weighed $307 \pm 6 \mathrm{~g}(n=15)$.

Serological titers and injection of tracers and capsaicin. The 93 rats studied in San Francisco were anesthetized with sodium methohexital $(60-75 \mathrm{mg} / \mathrm{kg}$ i.p.) and had $1 \mathrm{ml}$ of blood withdrawn for enzyme-linked immunosorbent assays of antibody titers to $M$. pulmonis, coronavirus, and Sendai virus (performed by Microbiological Associates Inc., Bethesda, MD). Titers to cilia-associated respiratory bacillus, Kilham rat virus, lymphocytic choriomeningitis virus, pneumonia virus of mice, reovirus type 3, and Toolan $\mathrm{H}-1$ virus were also measured in some of these rats.

The rats were then injected intravenously with a mixture containing $1.5 \%$ Monastral blue (Sigma Chemical Co., St. Louis, MO) and $1.5 \%$ Evans blue dye $(30 \mathrm{mg} / \mathrm{kg}$ of each tracer in $0.9 \% \mathrm{NaCl})$ for measurements of vascular permeability $(6,29)$. $\sim 15 \mathrm{~s}$ later, half of the rats had neurogenic inflammation produced by a $75-\mu \mathrm{g} / \mathrm{kg}$ dose of capsaicin (Sigma Chemical Co.) injected intravenously over $2 \mathrm{~min}$. This dose of capsaicin is at the threshold for increasing vascular permeability in the tracheas of pathogen-free rats and is the highest dose that the in fected rats could safely receive. ${ }^{2}$ The other half of the rats received an injection of the vehicle used for dissolving the capsaicin $(1 \mathrm{ml} / \mathrm{kg}$ of an aqueous solution containing $0.9 \% \mathrm{NaCl}, 1 \%$ ethanol, and $0.5 \%$ Tween 80 injected i.v. over $2 \mathrm{~min}$ ).

$5 \mathrm{~min}$ after the Evans blue and Monastral blue were injected, the rats were perfused through the ascending aorta with fixative (see below) at a pressure of $120 \mathrm{~mm} \mathrm{Hg}$. The perfusion washed out the intravascular tracers and preserved the tissues for the measurements of plasma extravasation and for the subsequent morphological studies.

Measurement of increase in vascular permeability. The 22-24 rats used in each experiment for measurements of vascular permeability were perfused for $2 \mathrm{~min}$ with $1 \%$ paraformaldehyde in $0.05 \mathrm{M}$ citrate buffer ( $\mathrm{pH}$ 3.5) (33). The rostral-most four cartilaginous rings were removed from each trachea, further fixed with $3 \%$ glutaraldehyde in 75 mM sodium cacodylate buffer ( $\mathrm{pH} 7.1$ ), and embedded in glycol methacrylate for the histological studies. The remaining portion of each trachea was cut open lengthwise along the ventral midline, transected at the carina, removed, blotted between pieces of bibulous paper, and weighed. The Evans blue was extracted from the trachea by incubation in three milliliters of $1 \%$ sodium Suramin (FBA Pharmaceuticals Division, Mobay Chemical Corp., New York, NY) in methanol for $4 \mathrm{~d}$ at $24^{\circ} \mathrm{C}$ (34). Previous studies had shown that, unlike formamide, Suramin extracts Evans blue from tracheas without altering the distribution of the Monastral blue and without destroying the tissue for morphological studies.

The optical density of the extracted dye in Suramin was measured with a spectrophotometer (Zeiss PMQ II) at a wavelength of $620 \mathrm{~nm}$, and the amount of Evans blue extravasated in the trachea was interpolated from a standard curve $(29,33)$. The Evans blue concentrations were expressed in two ways: nanograms of dye per trachea and nanograms of dye per milligram of trachea.

After the Evans blue was extracted, the tracheas were flattened as whole mounts $(6,35)$ and used to estimate the number of Monastral blue-labeled blood vessels by stereological point counting (12). The

\footnotetext{
${ }^{2}$ In previous studies, we used a capsaicin dose of $150 \mu \mathrm{g} / \mathrm{kg}$ injected intravenously over $2 \mathrm{~min}$ to evoke neurogenic inflammation in the respiratory tract $(12,13,20)$. In some pathogen-free rats, this dose of capsaicin caused brief periods of apnea during the injection but never caused death. Initially we planned to use this dose in the present study, but in preliminary experiments we learned that rats with M. pulmonis infections, particularly when exacerbated with ammonia, were so sensitive to capsaicin that a dose of $150 \mu \mathrm{g} / \mathrm{kg}$ i.v. caused death from apnea during the injection. Further experiments revealed that $75 \mu \mathrm{g} / \mathrm{kg}$, which is just at the threshold for increasing vascular permeability in the tracheas of pathogen-free rats (20), was the highest dose of capsaicin that the rats with severe $M$. pulmonis infections could safely tolerate.
}

area density of labeled vessels was measured in 15 regions of mucosa, each having an area of $0.2 \mathrm{~mm}^{2}$, between cartilaginous rings number 5 through 20 on the right side of each trachea. The measurements were made by superimposing a computer-generated multipurpose test lattice of 51 equally spaced points on a televised image of each of the 15 regions of trachea (12). Area densities were expressed as the average percentage of mucosal surface area occupied by labeled vessels in the 15 regions.

Tissue processing for histological studies. Tracheal cross-sections 3 $\mu \mathrm{m}$ in thickness, cut from specimens embedded in glycol methacrylate (JB-4 embedding kit, Polysciences Inc., Warrington, PA), were stained with $0.5 \%$ toluidine blue or Alcian blue-periodic acid Schiff(PAS) (12). The average thickness of the epithelium and lamina propria and the luminal circumference of the mucosa were measured on televised images of the cross-sections with a digitizing tablet. The mucosal thickness (epithelium plus lamina propria), mucosal area per section, and mucosal volume per millimeter of tracheal length were calculated from these values.

Mucosal blood vessels labeled with Monastral blue as well as those not labeled with the pigment were counted in tracheal sections from the capsaicin-treated rats; these values were expressed as the number of profiles per millimeter of luminal circumference and the number per cubic millimeter of mucosa. In addition, the extent of Monastral blue labeling per vessel was quantified by measuring the stained portion of the circumference of labeled vessel profiles and expressing this as a proportion of the total vessel circumference.

The number of glycoprotein-rich epithelial secretory cells in the Alcian blue-PAS stained cross-sections from the vehicle-treated rats was determined by counting all epithelial cell profiles that contained bright magenta granules (abundant neutral glycoproteins) or blue-purple granules (abundant acidic glycoproteins). The counts were expressed as the number of secretory cell profiles per millimeter of luminal circumference (12).

The two to six rats used in each experiment for electron microscopic studies were perfused with two glutaraldehyde-containing fixatives for $5 \mathrm{~min}$ each and the tracheas were removed (6). The four rostral-most cartilaginous rings were embedded in glycol methacrylate, and $1 \times 3 \mathrm{~mm}$ specimens of mucosa were cut from between cartilaginous rings of the caudal trachea, processed for electron microscopy, and embedded in epoxy resin (6). Sections $0.5 \mu \mathrm{m}$ in thickness from these specimens were stained with toluidine blue for light microscopy, and sections $\sim 50 \mathrm{~nm}$ in thickness were mounted on single slot specimen grids and stained with lead citrate for electron microscopy.

Eight $M$. pulmonis-infected rats, half of which were exposed to ammonia, and four pathogen-free rats were given capsaicin $(75 \mu \mathrm{g} / \mathrm{kg}$ i.v.), perfused with $1 \%$ paraformaldehyde in $0.05 \mathrm{M}$ phosphate buffer (pH 7.4), and then their tracheas were treated histochemically to stain the mucosal lymphoid tissue. For this purpose, the tracheas were removed, further fixed for $1-4 \mathrm{~h}$ at $4^{\circ} \mathrm{C}$, pinned to Sylgard slabs (Dow Corning Corp., Midland, MI), and washed in phosphate buffer containing hyaluronidase (Bovine testis type I-S; $1 \mathrm{U} / \mathrm{ml}$; Sigma) and tetraisopropylpyrophosphoramide (Iso-OMPA; $10^{-4} \mathrm{M}$; Sigma Chemical Co.) for $16 \mathrm{~h}$ at $4^{\circ} \mathrm{C}$. The tracheas were incubated for $8 \mathrm{~h}$ at $4^{\circ} \mathrm{C}$ in a medium containing acetylthiocholine and Iso-OMPA, which are respectively a substrate for localizing acetylcholinesterase and an inhibitor of nonspecific cholinesterase $(36,37)$. This reaction stains nerves and ganglia and also colors mucosal lymphoid tissue, presumably because of the esterase activity of some lymphocytes (38). The tracheas were then flattened as whole mounts (6).

The area density of the brown stained lymphoid tissue in these tracheas was quantified by stereological point counting in 10 regions of mucosa, five on each side, of the caudal-most cartilaginous portion of each trachea. Each region had an area of $1 \mathrm{~mm}^{2}$ and included portions of two cartilaginous rings. The measurements were made by superimposing a computed-generated multipurpose test lattice of 96 equally spaced points on televised images of each region of trachea. Area densities were expressed as proportions of the surface area of the tracheal mucosa. 
Statistical analysis. Average values are expressed as the mean \pm SE. The significance of differences between groups of data was evaluated by analysis of variance and Dunnett's multiple comparison test (39). Differences having $P$ values $<0.05$ were considered statistically significant. The significance of relationships between the area density of Monastral blue-labeled blood vessels and various other parameters was tested by simple linear regression.

\section{Results}

Quantitative cultures and antibody titers. At the end of the 4-wk experiments, $M$. pulmonis were found by culture to be present in the nose and trachea in concentrations ranging from $10^{4.9}$ to $10^{9.8}$ colony forming units per sample from the 12 infected rats used for this purpose and were also found in these concentrations in the lungs of 11 of these rats (Fig. $1 a$ ). The number of organisms cultured from the nose and lung was significantly greater in the infected rats exposed to ammonia than in those exposed to air (Fig. 1 a). M. pulmonis were not found in any of the rats inoculated with sterile culture medium.

All of the rats inoculated with $M$. pulmonis had serological titers to $M$. pulmonis, and those exposed to ammonia had significantly higher titers than did the other infected rats (Fig. $1 b$ ). None of the infected rats had significant titers to Sendai virus, coronavirus or any of the other respiratory pathogens analyzed. The rats inoculated with sterile culture medium did not have titers to $M$. pulmonis or any of the other pathogens.

The presence of $M$. pulmonis in the tracheas of infected rats was also confirmed by electron microscopy. The organisms were attached to the luminal surface of epithelial secretory cells (Fig. $2 a$ ) and ciliated cells (Fig. $2 b$ ). The mycoplasmas attached to ciliated cells were more closely associated with microvilli than with cilia (Fig. 2, $b$ and $c$ ).

Capsaicin-induced extravasation of Evans blue. The airways of the infected rats were unusually sensitive to capsaicin. For example, the tracheas of the air-exposed infected rats treated with $75 \mu \mathrm{g} / \mathrm{kg}$ of capsaicin contained seven times as much Evans blue $(7,669 \pm 1,324 \mathrm{ng} /$ trachea $)$ as did the tracheas of the infected rats treated with vehicle $(1,059 \pm 99 \mathrm{ng} /$ trachea $)$.
By contrast, the tracheas of the pathogen-free rats treated with the same dose of capsaicin contained little more dye than did those of pathogen-free rats treated with vehicle (Fig. $3 a$ ). The amount of Evans blue in the tracheas of the capsaicin-treated infected rats was 10 times that in the corresponding capsaicintreated pathogen-free controls $(767 \pm 137 \mathrm{ng} /$ trachea; Fig. $3 a)$.

The response to capsaicin was significantly larger in the ammonia-exposed infected rats than in the air-exposed infected rats, as indicated by the total amount of extravasated Evans blue in the trachea $(10,048 \pm 937 \mathrm{ng} /$ trachea; Fig. $3 a$ ). The amount of extravasation in these ammonia-exposed infected rats was eight times the baseline amount of extravasation found in such rats in the absence of capsaicin $(1,190 \pm 275 \mathrm{ng} /$ trachea). Ammonia exposure did not potentiate the capsaicin response of pathogen-free rats (Fig. $3 a$ ).

Capsaicin-induced extravasation of Monastral blue. The assumption that the abnormally large amount of capsaicin-induced extravasation of Evans blue in the infected rats was due to an increase in vascular permeability and not to hemodynamic changes was tested by determining the amount of Monastral blue labeling of the mucosal blood vessels. We found that the area density of labeled blood vessels in capsaicin-treated rats bore a close relationship to the amount of Evans blue per trachea $\left(r^{2}=0.90 ; y=134 x+702 ; n=62 ; P<0.001\right)$.

The air-exposed infected rats treated with capsaicin had 30 times the amount of vessel labeling (area density, $47 \pm 8 \%$ of mucosal surface area) as did the corresponding pathogen-free rats (area density, $1.6 \pm 0.5 \%$; Fig. $3 c$ ).

Exposure of the infected rats to ammonia amplified the response to capsaicin by $>50 \%$ (area density, $74 \pm 2 \% ; P$ $<0.01)$ compared to the values for the corresponding air-exposed rats (Fig. 3 c). However, ammonia exposure did not potentiate the capsaicin-induced extravasation of Monastral blue in uninfected rats (area density, $1.7 \pm 0.5 \%$; Fig. $3 c$ ). It appears, therefore, that this effect of ammonia required the presence of the infections and that the ammonia produced its effect by increasing the severity of the infections rather than by directly altering the neurogenic inflammatory response.

As further evidence that the severity of the infections in-

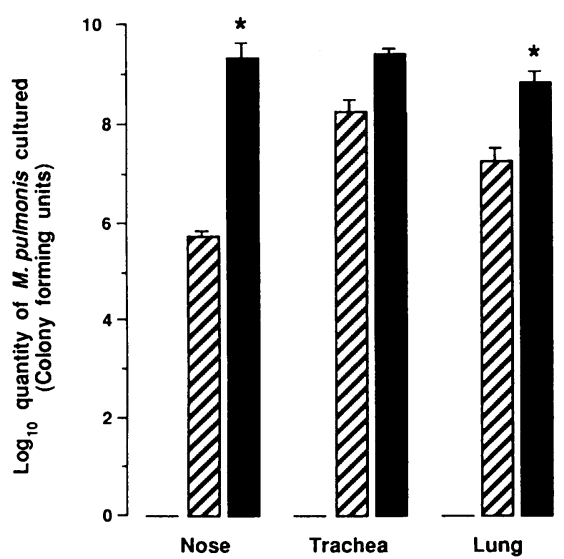

a.

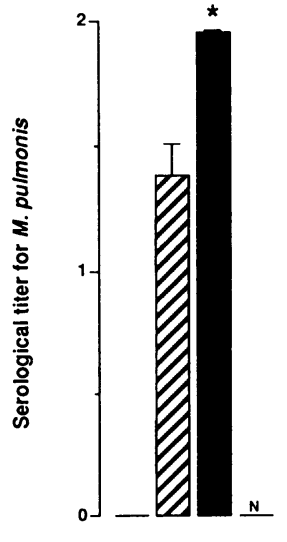

b.

Figure 1. (a) Number of $M$. pulmonis grown from homogenates of the nose, trachea and lung. Three groups of rats were studied $4 \mathrm{wk}$ after inoculation with $M$. pulmonis or with sterile culture medium (three pathogen-free, six $M$. pulmonis-infected, and six M. pulmonis infected with $\mathrm{NH}_{3}$ exposure). The number of organisms is expressed as the $\log _{10}$ of the mean $\pm \mathrm{SE}$ number of colony forming units. $(b)$ Serological titers to $M$. pulmonis antibodies in four groups of rats (40 pathogen-free, $16 \mathrm{M}$. pulmonis-infected, $14 \mathrm{M}$. pulmonis-infected with $\mathrm{NH}_{3}$ exposure, and 15 pathogen-free with $\mathrm{NH}_{3}$ exposure). The titers are expressed in assay units (mean $\pm \mathrm{SE}$; significant values exceed $0.17 \mathrm{U}$ ). Asterisks designate values which are significantly larger than corresponding values for rats infected with $M$. pulmonis but not exposed to ammonia, as determined by analysis of variance. 

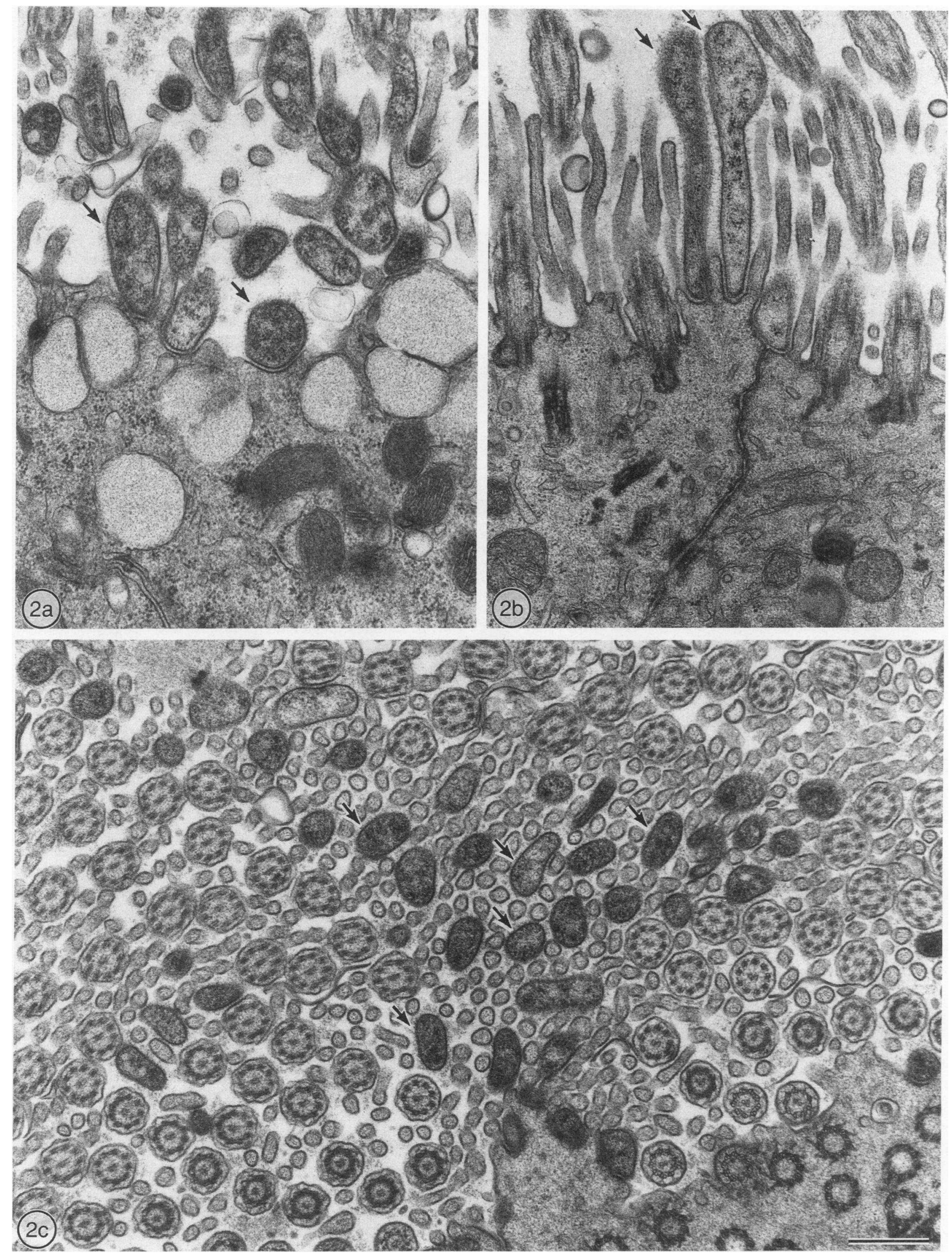


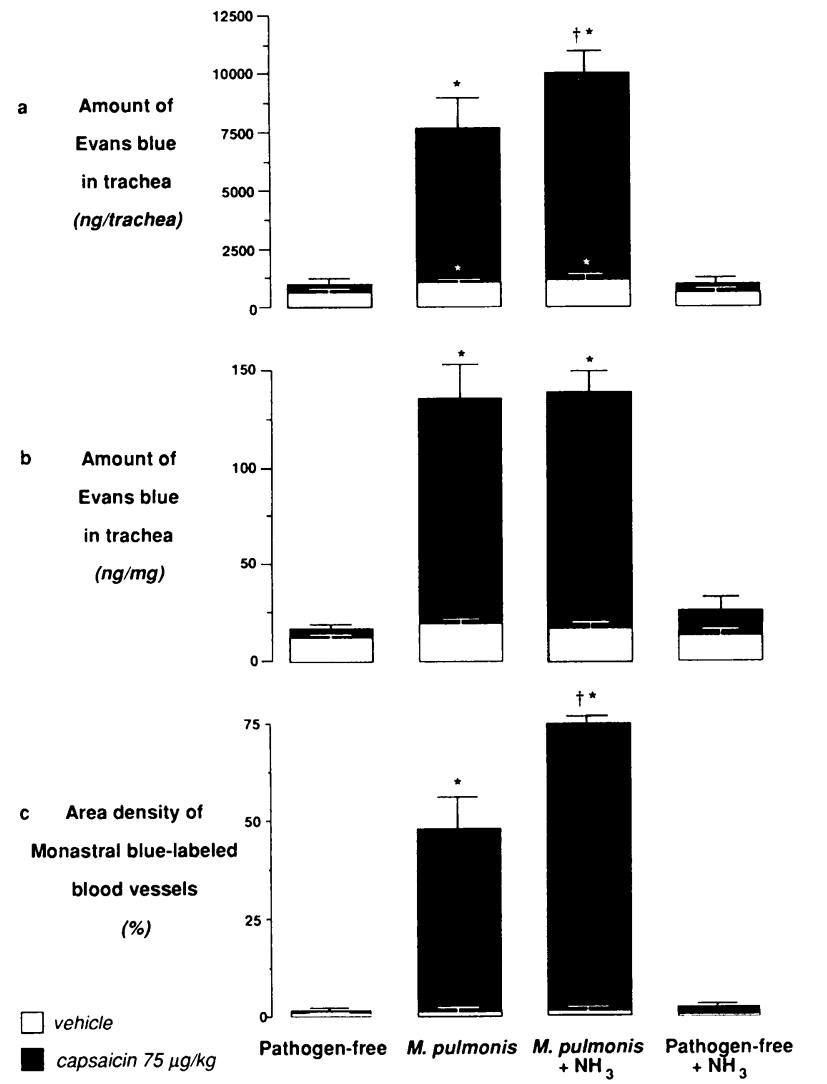

Figure 3. Histograms showing the effect of capsaicin (solid bars) or vehicle (open bars) on vascular permeability in the tracheas of four groups of rats: pathogen-free, $M$. pulmonis-infected, M. pulmonis infected with $\mathrm{NH}_{3}$ exposure, and pathogen-free with $\mathrm{NH}_{3}$ exposure. Values are the mean $\pm \mathrm{SE}$ ( $n=3-7$ rats per group) of the amounts of extravasated Evans blue dye, expressed as nanograms of dye per trachea $(a)$ and nanograms of dye per milligram of trachea $(b)$, or Monastral blue pigment, expressed as the percent of mucosal surface area in which labeled blood vessels were present $(c)$. Asterisks mark values that are significantly different from the corresponding values from pathogen-free rats $\left(^{*}\right)$ or from M. pulmonis-infected rats and pathogen-free rats $\left(\dagger^{*}\right)$ as determined by one-way analysis of variance $(P<0.01)$.

fluenced the magnitude of the neurogenic inflammatory response, the area density of the Monastral blue-labeled vessels in the tracheas of capsaicin-treated rats was by simple linear regression closely related to the titer of $M$. pulmonis antibodies in the blood $\left(r^{2}=0.93 ; y=0.026 x-0.012 ; P<0.001\right)$.

The question of whether the tracheas of the infected rats had an inherent abnormality in vascular permeability was addressed by comparing the amounts of extravasation in the various groups of vehicle-treated animals. Without capsaicin treatment, the infected rats had essentially the same area density of Monastral blue-labeled vessels as did the pathogen-free rats (Fig. $3 \mathrm{c}$ ). Similarly, the amounts of Evans blue in the tracheas of these two groups were approximately the same when differences in tracheal weight were taken into account (Fig. $3 b$ ).

Mucosal thickness and vascularity. As the weights of the tracheas of the infected rats exposed to air or to ammonia were 40 and $85 \%$ greater, respectively, than the weights of the pathogen-free rat tracheas (Table I), it was evident that there were likely to be corresponding increases in the amounts of mucosal tissue. Indeed, histological studies revealed that the tracheal mucosas in the two groups of infected rats were 87 and $290 \%$ thicker, respectively, than those of the controls (Table I). Accordingly, the volumes of the mucosa were 60 and $250 \%$ greater, respectively, in these two groups than in the controls (Table I). The increase in mucosal thickness in the infected rats resulted from an increase in the height of the epithelium (see below) and a thickening of the lamina propria (Table I) due to the influx of lymphoid cells and other chronic inflammatory changes.

The possible contribution of the increase in mucosal tissue mass to the augmented extravasation of the tracers was assessed by comparing values normalized for tracheal weight. Evans blue values, expressed as nanograms of dye per milligram of trachea, averaged eight times larger in the capsaicin-treated, air-exposed infected rats than in the pathogen-free controls (Fig. $3 b ; P<0.001$ ). Similarly, Monastral blue area densities normalized for tracheal weight averaged 21 times higher $(P$ $<0.001)$ in the capsaicin-treated, air-exposed infected rats $(0.84 \pm 0.14 \%$ per $\mathrm{mg})$ than in the controls $(0.04 \pm 0.01 \%$ per $\mathrm{mg})$. However, the normalized Monastral blue values for the ammonia-exposed infected rats $(1.00 \pm 0.03 \%$ per $\mathrm{mg})$ were only marginally greater than those for the corresponding airexposed rats $(P=0.08)$, and the normalized Evans blue values for the two groups of infected rats were not significantly different from one another (Fig. $3 b$ ).

For these normalized values to be meaningful, the abnormally thick mucosa would have to be accompanied by a corresponding increase in the number of blood vessels responsible for the capsaicin-induced plasma extravasation. Histological studies showed that the mucosa of infected rats was indeed more vascular than that of the pathogen-free controls: In the infected rats exposed to air and in those exposed to ammonia, the blood vessel profiles per millimeter of luminal surface were 30 and $100 \%$ more numerous, respectively, than in the controls (Table I). However, the increase in mucosal volume exceeded the increase in vascularity to such an extent that the numbers of vessels per cubic millimeter of mucosa decreased 30 and $50 \%$, respectively, in the two groups of infected rats (Table I). Consequently, the normalization of the values for tracheal weight overcorrected for the increase in vascularity.

Monastral blue-labeled blood vessels. The abnormally large amount of extravasation in the tracheas of capsaicintreated infected rats could have resulted from an increase in the number of blood vessels that are responsive to mediators released by capsaicin or from an increase in the responsiveness of individual vessels. Our analysis of the vessels in histological

Figure 2. Electron micrographs showing M. pulmonis attached to tracheal epithelial cells of rats inoculated with organisms and then exposed to ammonia for $4 \mathrm{wk}$. (a) Mycoplasma (arrows) attached to the apical surface of an epithelial secretory cell. ( $b$ and $c$ ) Organisms (arrows) attached to the apical plasma membrane and microvillous processes of ciliated cells. (c) Cross-section through a cluster of microvilli and cilia illustrating the abundance of mycoplasma near microvilli. Scale bar, $0.5 \mu \mathrm{m}$. 
Table I. Effect of M. pulmonis Infections and Ammonia Exposure on the Weight, Mucosal Thickness, and Number of Blood Vessels in Rat Tracheas

\begin{tabular}{|c|c|c|c|c|}
\hline & \multirow[b]{2}{*}{ Pathogen-free rats } & \multicolumn{3}{|c|}{ Rats with infections and/or $\mathrm{NH}_{3}$ exposure } \\
\hline & & M. pulmonis & M. pulmonis $+\mathrm{NH}_{3}$ & Pathogen-free $+\mathrm{NH}_{3}$ \\
\hline Tracheal weight $(m g)$ & $41 \pm 4$ & $58 \pm 3^{*}$ & $76 \pm 2^{\ddagger}$ & $36 \pm 2$ \\
\hline Thickness of mucosa $(\mu \mathrm{m})$ & $93 \pm 12$ & $174 \pm 18^{*}$ & $366 \pm 18^{\ddagger}$ & $89 \pm 3$ \\
\hline \multicolumn{5}{|l|}{ Thickness of lamina propria } \\
\hline (\% total mucosal thickness) & $70 \pm 3$ & $70 \pm 5$ & $93 \pm 0.4^{\ddagger}$ & $71 \pm 2$ \\
\hline \multicolumn{5}{|l|}{ Volume of mucosa } \\
\hline$\left(\mathrm{mm}^{3} / \mathrm{mm}\right.$ tracheal length $)$ & $0.52 \pm 0.07$ & $0.84 \pm 0.1^{*}$ & $1.85 \pm 0.1^{\ddagger}$ & $0.52 \pm 0.05$ \\
\hline No. vessel profiles per mm mucosa & $17 \pm 2$ & $22 \pm 3$ & $35 \pm 2^{\ddagger}$ & $17 \pm 2$ \\
\hline No. of vessels per $\mathrm{mm}^{3}$ mucosa & $186 \pm 10$ & $128 \pm 6^{*}$ & $95 \pm 7^{\ddagger}$ & $188 \pm 17$ \\
\hline
\end{tabular}

Values are means $\pm \mathrm{SE}$ of tracheal weights and data from tracheal cross-sections from four capsaicin-treated rats in each group. The mucosal thickness represents the combined thicknesses of the epithelium and the lamina propria. Mucosal volumes were calculated from the mucosal thickness and the luminal circumference of the tracheas and are expressed as cubic millimeters of tissue per millimeter of tracheal length. The total number of mucosal blood vessels is expressed as the number of vessel profiles per millimeter of luminal circumference. The number of vessels per unit volume was calculated from the number of vessel profiles per $\mathrm{mm}^{2}$ of mucosa in tracheal cross-sections. ${ }^{* \pm}$ Values that are significantly different from the corresponding values from ${ }^{*}$ pathogen-free rats or from ${ }^{\ddagger} M$. pulmonis-infected rats and pathogen-free rats, as determined by one-way analysis of variance $(P<0.05)$.

sections (Table II) revealed that the infections caused the following changes: $(a)$ The number of Monastral blue-labeled vessel profiles per millimeter of mucosa increased fivefold in the infected rats exposed to air and increased 10-fold in the infected rats exposed to ammonia, compared to the corresponding values for the pathogen-free rats. In all groups of rats the labeled vessels were postcapillary venules or collecting venules some 7-80 $\mu \mathrm{m}$ in diameter. (b) The number of unlabeled blood vessel profiles per millimeter of mucosa decreased significantly both in the infected rats exposed to air $(-43 \%)$ and in those exposed to ammonia $(-57 \%)$. (c) The proportion of vessels labeled with Monastral blue increased from $14 \%$ of the total in the pathogen-free rats to 63 and $82 \%$ in the two groups of infected rats. $(d)$ The amount of labeling of individual vessels, as indicated by the proportion of the vessel perimeter stained with Monastral blue, increased from $13 \%$ in the pathogen-free rats to 62 and $77 \%$ in the two groups of infected rats. All of the values for the infected rats differed significantly from the corresponding values for the pathogen-free controls (Table
II). Furthermore, all of the measurements for Monastral bluelabeled vessels in the ammonia-exposed infected rats were significantly larger than the corresponding values for the air-exposed infected rats (Table II).

Pathological changes in the tracheal mucosa. The tracheal mucosa of rats with $M$. pulmonis infections had at least three additional abnormalities. First, the thickness of the epithelium and the number of ciliated cells were conspicuously increased (Fig. 4, $a$ and $b$, Table III). When the infections were exacerbated by ammonia, the epithelium in some regions was even thicker and had cryptlike infoldings (Fig. $4 c$ ) and in other regions, particularly over accumulations of lymphoid cells, was unusually thin, so the average thickness of the epithelium was about the same as that of the other infected rats (Table III).

Second, the number of profiles of Alcian blue-PAS stained epithelial mucous cells was some 45 times greater in the air-exposed infected rats than in the pathogen-free rats (Figs. 4, $d$ and $e$, Table III). Such cell profiles were even more abundant in the epithelium of the ammonia-exposed infected rats (Table III),

Table II. Effect of M. pulmonis Infections and Ammonia Exposure on the Number of Monastral Blue-labeled Blood Vessels and the Proportion of Vessel Perimeter Stained with Monastral Blue in Rat Tracheal Mucosa

\begin{tabular}{|c|c|c|c|c|}
\hline & \multirow[b]{2}{*}{ Pathogen-free rats } & \multicolumn{3}{|c|}{ Rats with infections and/or $\mathrm{NH}_{3}$ exposure } \\
\hline & & M. pulmonis & M. pulmonis $+\mathrm{NH}_{3}$ & Pathogen-free $+\mathrm{NH}_{3}$ \\
\hline No. Monastral blue-labeled vessel profiles ( per $\mathrm{mm}$ ) & $2 \pm 0.7$ & $15 \pm 3^{*}$ & $29 \pm 3^{\ddagger}$ & $4 \pm 1$ \\
\hline No. unlabeled vessel profiles (per $\mathrm{mm}$ ) & $14 \pm 1$ & $8 \pm 1^{*}$ & $6 \pm 1^{*}$ & $12 \pm 2$ \\
\hline Proportion of vessel profiles labeled with Monastral blue (\%) & $14 \pm 4$ & $63 \pm 7^{*}$ & $82 \pm 3^{\ddagger}$ & $27 \pm 6$ \\
\hline Proportion of vessel perimeter stained with Monastral blue (\%) & $13 \pm 5$ & $62 \pm 3^{*}$ & $77 \pm 3^{\ddagger}$ & $18 \pm 4$ \\
\hline
\end{tabular}

Values are means $\pm \mathrm{SE}$ of data obtained from tracheal cross-sections from four capsaicin-treated rats in each group. The number of labeled and unlabeled blood vessels is expressed as the number of vessel profiles per millimeter of luminal circumference. The relative frequency of Monastral blue-labeled vessels is expressed as a percentage of the total number of vessel profiles. The amount of labeling of individual vessels, determined in 10 labeled vessels per cross-section by measuring the length of perimeter stained with Monastral blue, is expressed as a percentage of the total vessel circumference. ${ }^{* \ddagger}$ Values that are significantly different from the corresponding values from ${ }^{*}$ pathogen-free rats or from ${ }^{\ddagger} M$. pulmonis-infected rats and pathogen-free rats, as determined by one-way analysis of variance $(P<0.05)$. 

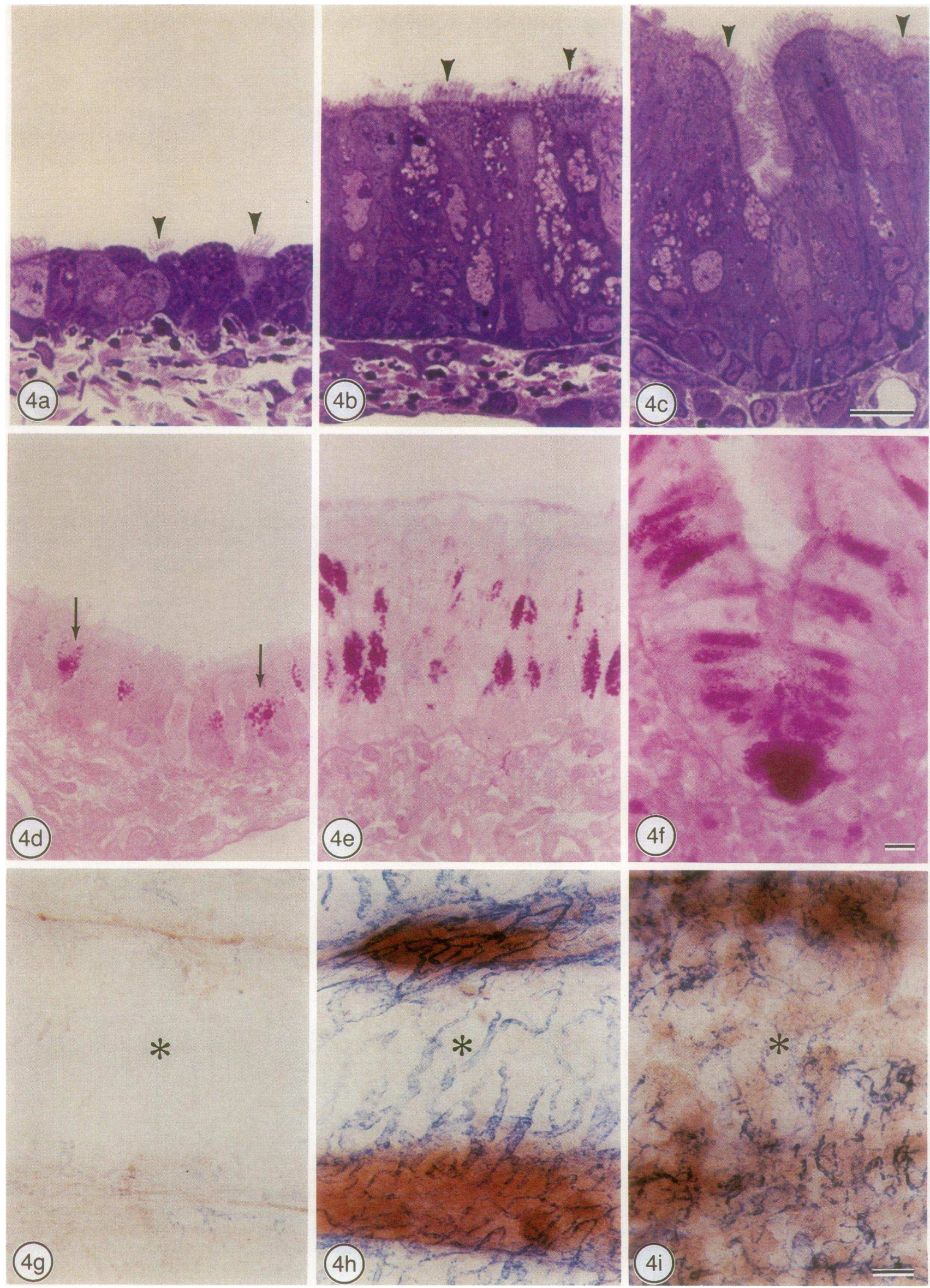
Table III. Effect of M. pulmonis Infections and Ammonia Exposure on Epithelial Height, Number of Epithelial Mucous Cells, and Amount of Mucosal Lymphoid Tissue in Rat Tracheas

\begin{tabular}{|c|c|c|c|c|}
\hline & \multirow[b]{2}{*}{ Pathogen-free rats } & \multicolumn{3}{|c|}{ Rats with infections and/or $\mathrm{NH}_{3}$ exposure } \\
\hline & & M. pulmonis & M. pulmonis $+\mathrm{NH}_{3}$ & Pathogen-free $+\mathrm{NH}_{3}$ \\
\hline Epithelial height $(\mu m)$ & $22 \pm 1$ & $51 \pm 3^{*}$ & $48 \pm 6^{*}$ & $24 \pm 1$ \\
\hline Epithelial mucous cell profiles per $\mathrm{mm}$ & $1 \pm 0.4$ & $45 \pm 12^{*}$ & $100 \pm 16^{\ddagger}$ & $1 \pm 0.5$ \\
\hline Mucosal lymphoid tissue area density (\%) & $0.1 \pm 0.1$ & $45 \pm 6^{*}$ & $76 \pm 11^{\ddagger}$ & ND \\
\hline
\end{tabular}

Values are means $\pm \mathrm{SE}$ for the tracheas of three to five rats in each group. These data came from the tracheas of vehicle-treated rats, with the exception of the measurements of mucosal lymphoid tissue which were made on capsaicin-treated rat tracheas stained especially for this purpose (see Methods). The number of epithelial mucous cells reflects the total number of epithelial cell profiles with bright magenta or bluepurple granules per millimeter of epithelium in Alcian blue-PAS stained tracheal cross-sections. The area densities of mucosal lymphoid tissue are expressed as a percentage of total mucosal surface area. ${ }^{* \ddagger}$ Values that are significantly different from the corresponding values from ${ }^{*}$ pathogen-free rats or from ${ }^{\ddagger} M$. pulmonis-infected rats and pathogen-free rats, as determined by one-way analysis of variance $(P<0.01)$. ND, not determined.

where they were particularly numerous and heavily laden with glycoprotein-rich secretory granules at the base of the cryptlike infoldings (Fig. $4 \mathrm{f}$ ). Consistent with these observations, the secretory cells, unlike the serous cells typical of the tracheal epithelium of pathogen-free rats (Fig. $5 a$ and $b$ ), had the ultrastructural features of mucous cells (Figs. $5 c$ and $d$ ).

Third, aggregates of lymphoid cells, which were rare or absent in the tracheal mucosa of pathogen-free rats (Fig. $4 \mathrm{~g}$, Table III), occupied nearly half of the mucosal surface in the air-exposed infected rats and three-quarters of the mucosa in the ammonia-exposed infected rats (Fig. $4 h$ and $i$, Table III).

\section{Discussion}

This study revealed that $M$. pulmonis infections in rats potentiated the plasma extravasation produced in the respiratory tract by the sensory nerve stimulant capsaicin. This potentiation was evident 4 wk after the rats were inoculated with $M$. pulmonis, at a time the organisms were abundant in the airways despite the presence of a prominent immunologic response. Exposure to ammonia amplified the response to capsaicin in the infected rats but not in the pathogen-free rats. We interpret these results as evidence that the chronic inflammation produced by mycoplasmal infections makes the airways abnormally sensitive to sensory nerve stimuli which evoke neurogenic inflammation and that ammonia can amplify this sensitivity by exacerbating the infections.

The design of our experiments took into account several issues. First was whether the increase in vascular permeability, which we attributed to neurogenic inflammation, could instead have been a nonspecific effect of the infection or ammonia exposure. To deal with this issue, we determined the amount of plasma extravasation in the tracheas of each group of rats in the absence of capsaicin. These measurements showed that neither the infection nor the ammonia exposure itself significantly increased vascular permeability.

We used capsaicin as a sensory nerve stimulant because it can produce neurogenic inflammation in the respiratory tract in a dose-dependent fashion (20). An intravenous dose of 75 $\mu \mathrm{g} / \mathrm{kg}$ caused a barely detectable amount of plasma extravasation in the tracheas of pathogen-free rats but had very potent effects in $M$. pulmonis-infected rats. To interpret this finding, we needed to know whether the abnormally large amount of extravasation in the infected rats was due to a potentiation of the vascular permeability increase associated with neurogenic inflammation or to a potentiation of the hemodynamic changes evoked by the capsaicin (31). For this reason we used two tracers, one (Evans blue) that follows the movement of albumin and thus can be influenced by hemodynamic changes, and the other (Monastral blue) which is sufficiently large (50$300 \mathrm{~nm}$ ) that it can leave tracheal blood vessels only at sites of increased permeability $(6,30,35)$. The close correspondence of the results obtained with the two tracers is consistent with the conclusion that the capsaicin-induced extravasation of both tracers in the infected rats was due to an increase in vascular permeability.

Another question we addressed was whether the abnormally large amounts of Evans blue and Monastral blue in the tracheas of the infected rats could be explained by a nonspecific increase in the amount of mucosal tissue instead of by a change

Figure 4. Light micrographs showing morphological differences in the tracheas of three groups of rats: pathogen-free $(a, d, g), M . p u l m o n i s-$ infected $(b, e, h)$, and $M$. pulmonis infected with $\mathrm{NH}_{3}$ exposure $(c, f, i) . a-c$ compare the thin epithelium with sparse ciliated cells in the trachea of a pathogen-free rat $(a)$ and the abnormally thick epithelium with abundant ciliated cells (arrowheads) in infected rats $(b$ and $c$ ). These figures also compare the densely stained serous granules in epithelial secretory cells of a pathogen-free rat $(a)$ and the pale staining mucous granules in the secretory cells of the infected rats $(b$ and $c) .0 .5 \mu \mathrm{m}$ epoxy sections stained with toluidine blue. Scale bar, $10 \mu \mathrm{m} . d-f$ contrast the pale Alcian blue-PAS staining in the epithelium of a pathogen-free rat, except for the granules in globule leukocytes $(d$, arrows), the prominently stained magenta secretory granules of mucous cells in the epithelium of an infected rat $(e)$, and the even more abundant mucous cells (magenta) in an infected rat exposed to $\mathrm{NH}_{3}(f) .3 \mu \mathrm{m}$ methacrylate sections. Scale bar, $10 \mu \mathrm{m} . \mathrm{g}-i$ compare the number of Monastral blue-labeled blood vessels (blue structures) and the amount of mucosal lymphoid tissue (brown regions) in tracheal whole mounts from a capsaicin-treated pathogen-free rat ( $g$, no lymphoid tissue), infected rat ( $h$, two aggregates of lymphoid tissue), and infected rat exposed to $\mathrm{NH}_{3}(i$, many aggregates of lymphoid tissue). The whole mounts are viewed from the luminal surface and show the mucosa overlying a portion of a cartilaginous ring $\left({ }^{*}\right)$ bordered by intercartilaginous connective tissue. Scale bar, $100 \mu \mathrm{m}$. 

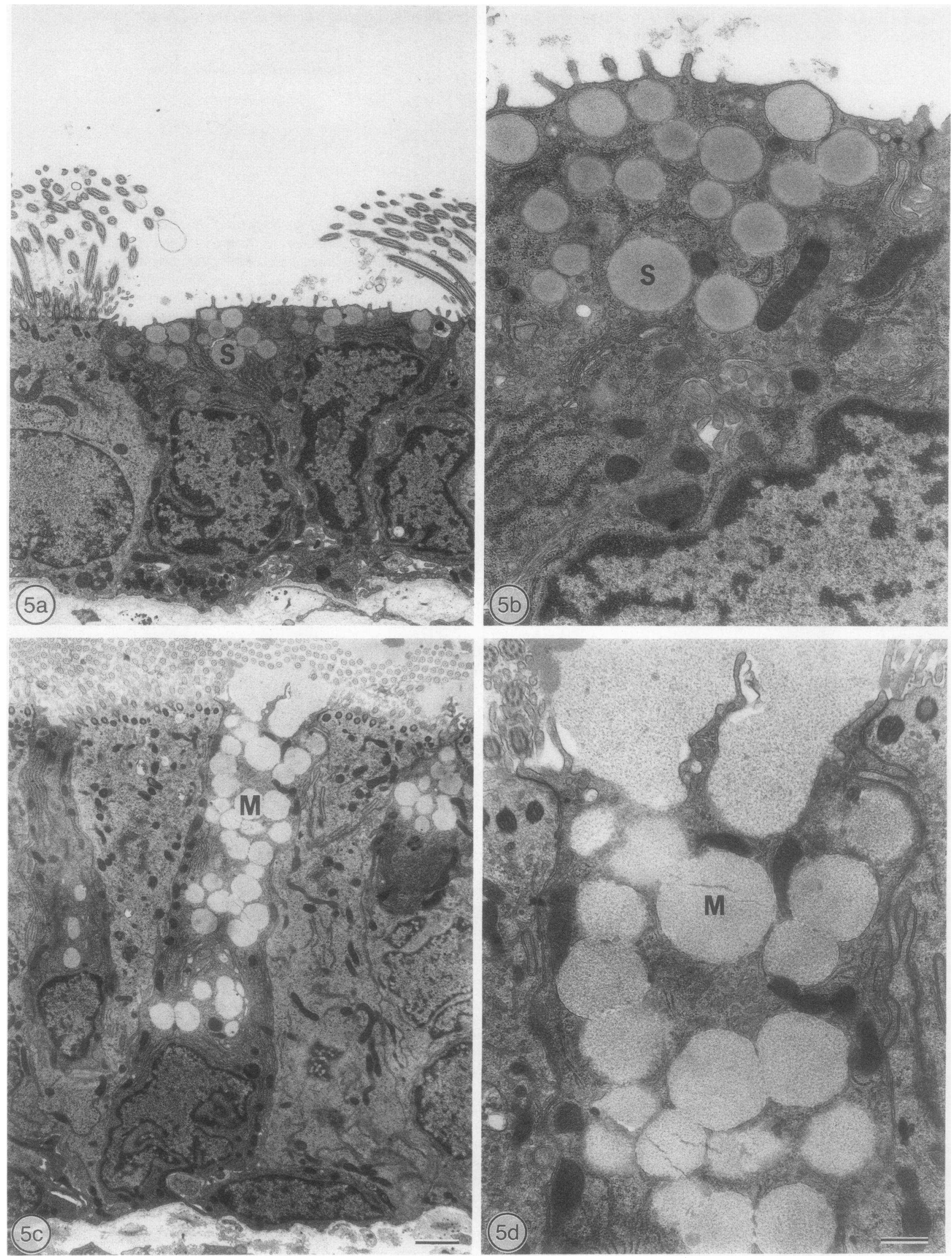

Figure 5. Electron micrographs comparing the secretory cells in the tracheal epithelium of a pathogen-free rat $(a$ and $b)$ with those of a rat infected by $M$. pulmonis ( $c$ and $d$ ). The granules in the tall, columnar mucous cell $(M)$ of the infected rat are larger, more numerous, and less electrondense than those in the cuboidal serous cell $(S)$ of the pathogen-free rat. Scale bars, $2 \mu \mathrm{m}$ in $a$ and $c, 0.5 \mu \mathrm{m}$ in $b$ and $d$. 
in the neurogenic inflammatory response, per se. This possibility was examined by normalizing the amounts of the extravasated tracers for differences in tracheal weight, which served as an index of mucosal tissue mass. Such a normalization seemed appropriate because the tracheas of the infected rats were heavier than those of the pathogen-free controls and this increased weight was in large part due to a thickening of the mucosa. Despite this normalization, the values for capsaicininduced plasma extravasation were significantly larger in the infected rats than in the controls. Thus, the infection-induced potentiation of neurogenic plasma extravasation could not be explained simply by differences in tracheal weight. Furthermore, as the thickening of the mucosa was not accompanied by a proportionate increase in the number of mucosal blood vessels, the normalization for tracheal weight overcorrected for the increase in vascularity and erroneously reduced the differences between some of the groups. For example, the normalized Evans blue concentrations and the normalized Monastral blue area densities did not show the difference in the capsaicin-sensitivities of the two groups of infected rats (air-exposed vs. ammonia-exposed). However, this difference was clearly demonstrated by comparisons of the number of Monastral blue labeled vessels, the proportion of vessels that were labeled, and the extent of labeling of individual vessels.

A final issue was whether the rats acquired viral infections before or during the experiments, which would have obscured the role of the $M$. pulmonis infections in the potentiation of neurogenic inflammation. This question needed to be addressed because viral infections can potentiate neurogenic inflammation (19) and can make mycoplasmal infections worse $(21,22)$. These complicating factors were avoided, first, by using rats that had been raised under barrier conditions and were known to be pathogen-free at the outset and, second, by housing the rats under barrier conditions during the 4-wk experiment. As a result, none of the animals used in the study had antibody titers to any of the nine pathogens tested except for $M$. pulmonis, and the rats that were not intentionally inoculated with $M$. pulmonis did not have titers to any of the organisms.

Comparison with effects of other infections. Our data from rats with $M$. pulmonis infections differ in at least two ways from those obtained in similar studies of viral infections. First, the potentiation of neurogenic inflammation by $M$. pulmonis infections was present $4 \mathrm{wk}$ after inoculation and probably was permanent, as these infections persist throughout life. By comparison, the potentiation of neurogenic inflammation by Sendai virus infections has only been detected $6 \mathrm{~d}$ after inoculation (19). In adult rats, Sendai virus infections peak within a week, and the resulting pathological changes in the trachea and bronchi resolve in 10-17 d $(40,41)$.

Second, $M$. pulmonis infections have a more potent effect on neurogenic plasma extravasation than do Sendai virus infections. For example, in M. pulmonis-infected rats, the 75- $\mathrm{g}$ / $\mathrm{kg}$ dose of capsaicin produced extensive extravasation in the tracheal mucosa (area density of Monastral blue-labeled blood vessels, $47 \%$ ) and had an even larger effect when the infection was exacerbated by ammonia (area density, 74\%). In contrast, at the peak of a Sendai virus infection, this dose of capsaicin evokes much less extravasation (area density, 17\%)(19). Part of this difference can be attributed to the proliferation of mediator-sensitive postcapillary venules in the airway mucosa of $M$. pulmonis infected rats (see below).
The changes we found in the airways of rats inoculated with $M$. pulmonis resembled those observed previously in rats with naturally acquired respiratory tract infections caused by Sendai virus and coronavirus in combination with $M$. pulmonis (12, $20)$. In both the naturally infected and the inoculated animals, the potentiation of neurogenic plasma extravasation was strikingly large, had a long duration, and was accompanied by distinctive morphological alterations in the tracheal mucosa. In particular, the mucosa had an abnormally large number of Monastral blue-labeled postcapillary venules, was abnormally thick, and contained abundant lymphoid tissue $(12,42)$. Furthermore, the epithelium was more than twice normal in thickness and contained unusually large numbers of ciliated cells and mucous cells. Because of these similarities, we suspect that M. pulmonis, not Sendai virus or coronavirus, was the pathogen responsible for the potentiation of neurogenic inflammation in the rats with the combined infections.

Mechanism of potentiation of neurogenic plasma extravasation. The presence of an abnormally large number of Monastral blue-labeled postcapillary venules in the tracheas of the capsaicin-treated infected rats indicates that the infections increase the number of vessels involved in neurogenic plasma extravasation. Similarly, the augmented staining of individual venules is evidence that the vessels become more responsive to inflammatory mediators. Together, these findings suggest that the infections increase the number of sites at which such mediators can increase vascular permeability. However, it is not known whether tachykinins act directly on the postcapillary venules and whether tachykinin receptors become more numerous when the vessels proliferate. Alternatively, the inflammatory cells entering the mucosa as a result of the infection may release mediators that act synergistically with tachykinins.

An increase in the number of sensory nerves that release tachykinins could contribute to the potentiated response to capsaicin. However, this is unlikely to be the only change, because infected rats are unusually responsive to substance $P$ (20), which acts independent of the sensory nerves $(3,27)$. An additional change that may be involved is a reduction in the activity of neutral endopeptidase (14). A decrease in the activity of this enzyme augments the effects of endogenous and exogenous tachykinins $(14,18)$, which are normally degraded by this enzyme (43-45).

Whatever the mechanism of the potentiation, $M$. pulmonis are unlikely to affect nerves or blood vessels directly, as they are extracellular parasites which attach to the luminal surface of airway epithelial cells (46). Although the basis of the organisms' pathogenicity is not known, they can survive in the airways for extended periods of time despite the immunologic response they evoke (47). Part of this response involves the production of specific IgA, IgG, and IgM antibodies, and part is a manifestation of the nonspecific mitogenic effect of the organisms on lymphocytes $(48,49)$. Thus, mycoplasmal antigens and mitogens as well as cytokines from host inflammatory cells may contribute to the changes we observed.

Clinical relevance. The inhalation of irritants produces abnormally severe bronchoconstriction in people with asthma (50). This susceptibility to conditions that evoke bronchoconstriction is long-lasting, and thus differs from the transient bronchial hyperreactivity seen in some otherwise normal adults with viral respiratory tract infections (51).

An alteration in sensory nerve function could be a factor in such bronchial hyperreactivity. Previous studies have shown 
that viral infections can potentiate the bronchoconstrictor responses to substance $P(14,17,18)$, perhaps through a reduction in neutral endopeptidase activity $(14,18)$. The present study revealed that $M$. pulmonis infections make the sensory nerves of the airways abnormally sensitive to stimuli with respect to their mediation of neurogenic inflammation. It is possible that such nerves are also abnormally sensitive with respect to their reflex effects, as we observed that capsaicin had an unusually potent effect on the pattern of breathing in rats with severe $M$. pulmonis infections. Some of the infected rats became apneic and died while receiving a dose of capsaicin that was readily tolerated by the pathogen-free rats.

The parallels between the changes in $M$. pulmonis-infected rats and the changes associated with asthma in humans are worthy of further study. Both are long-lasting conditions characterized by chronic inflammation of the airways. Both are associated with the development of an abnormal sensitivity to irritants. Both can be exacerbated by other conditions such as viral infections and inhaled irritants, and both are associated with changes that can be of extraordinary magnitude. We suspect that the elucidation of the mechanism by which $M$. pulmonis infections potentiate neurogenic inflammation will help in understanding the basis of the sustained bronchial hyperresponsiveness found in people with asthma.

Conclusions. We conclude that $M$. pulmonis infections in rats, in the absence of viral infections or other promoters, potentiate neurogenic plasma extravasation in the respiratory tract. This potentiation is evidenced by a long-lasting sensitization to capsaicin, which produces an abnormally large increase in the permeability of venules in the airway mucosa. When the infections are exacerbated by exposure to ammonia, the animals become even more susceptible to neurogenic inflammation. However, ammonia exposure does not sensitize uninfected animals, and neither the ammonia exposure nor the $M$. pulmonis infections increase vascular permeability in the absence of sensory nerve stimulation. Our experiments emphasize the importance of $M$. pulmonis infections as factors that can cause a potent, long-lasting increase in the responsiveness of the respiratory tract.

\section{Acknowledgments}

The authors thank Ms. Amy Haskell at University of California, San Francisco, for providing expert assistance in handling the animals, preparing the tissues for light and electron microscopy, obtaining the morphometric data, and preparing the micrographs. We also express our appreciation to Dr. Maureen K. Davidson at the Birmingham Veterans Administration Medical Center and the University of Alabama at Birmingham for assistance in quantitatively culturing Mycoplasma pulmonis.

This study was supported in part by National Heart, Lung, and Blood Institute Program Project Grant HL-24136 (DMM) from the United States Public Health Service and by funds from the United States Veterans Administration Research Service (JRL).

\section{References}

1. Jancso, N. 1960. Role of the nerve terminals in the mechanism of inflammatory reactions. Bull. Millard Fillmore Hosp. 7:53-77.

2. Jancso, N., A. Jancso-Gabor, and J. Szolcsanyi. 1967. Direct evidence for neurogenic inflammation and its prevention by denervation and by pretreatment with capsaicin. Br. J. Pharmacol. Chemother. 31:138-151.

3. Lundberg, J. M., and A. Saria. 1983. Capsaicin-induced desensitization of airway mucosa to cigarette smoke, mechanical and chemical irritants. Nature (Lond.) 302:251-253.
4. Lundblad, L. 1984. Protective reflexes and vascular effects in the nasal mucosa elicited by activation of capsaicin-sensitive substance P-immunoreactive trigeminal neurons. Acta Physiol. Scand. S529:5-42.

5. Persson, C. G. A., I. Erjefalt, and P. Andersson. 1986. Leakage of macromolecules from guinea-pig tracheobronchial microcirculation. Effects of allergen, leukotrienes, tachykinins, and anti-asthma drugs. Acta Physiol. Scand. 127:95105.

6. McDonald, D. M. 1988. Neurogenic inflammation in the rat trachea. I. Changes in venules, leucocytes, and epithelial cells. J. Neurocytol. 17:583-603.

7. Martling, C.-R., R. Matran, K. Alving, J. S. Lacroix, and J. M. Lundberg. 1989. Vagal vasodilatory mechanisms in the pig bronchial circulation preferentially involves sensory nerves. Neurosci. Lett. 96:306-311.

8. Kowalski, M. L., A. Didier, and M. A. Kaliner. 1989. Neurogenic inflammation in the airways. I. Neurogenic stimulation induces plasma protein extravasation into the rat airway lumen. Am. Rev. Respir. Dis. 140:101-109.

9. Lundberg, J. M., A. Saria, E. Brodin, E. Rosell, and K. Folkers. 1983. A substance $P$ antagonist inhibits vagally induced increase in vascular permeability and bronchial smooth muscle contraction in the guinea pig. Proc. Natl. Acad. Sci. USA. 80:1120-1124.

10. Belvisi, M. G., D. F. Rogers, and P. J. Barnes. 1989. Neurogenic plasma extravasation: inhibition by morphine in guinea pig airways in vivo. $J$. Appl. Physiol. 66:268-272.

11. Wei, E. T., and J. G. Kiang. 1987. Inhibition of protein exudation from the trachea by corticotropin-releasing factor. Europ. J. Pharmacol. 140:63-67.

12. Huang, H.-T., A. Haskell, and D. M. McDonald. 1989. Changes in epithelial secretory cells and potentiation of neurogenic inflammation in the trachea of rats with respiratory tract infections. Anat. Embryol. 180:325-341.

13. Piedimonte, G., D. M. McDonald, and J. A. Nadel. 1990. Glucocorticoids inhibit neurogenic plasma extravasation and prevent virus-potentiated extravasation in the rat trachea. J. Clin. Invest. 86:1409-1415.

14. Sekizawa, K., J. Tamaoki, J. A. Nadel, and D. B. Borson. 1987. Enkephalinase inhibitor potentiates substance P- and electrically induced contraction in ferret trachea. J. Appl. Physiol. 63:1401-1405.

15. Borson, D. B., J. J. Brokaw, K. Sekizawa, D. M. McDonald, and J. A. Nadel. 1989. Neutral endopeptidase and neurogenic inflammation in rats with respiratory infections. J. Appl. Physiol. 66:2653-2658.

16. Umeno, E., J. A. Nadel, H.-T. Huang, and D. M. McDonald. 1989. Inhibition of neutral endopeptidase potentiates neurogenic inflammation in the rat trachea. J. Appl. Physiol. 66:2647-2652.

17. Saban, R., E. C. Dick, R. I. Fishleder, and C. K. Buckner. 1987. Enhancement by parainfluenza 3 infection of contractile responses to substance $\mathbf{P}$ and capsaicin in airway smooth muscle from the guinea pig. Am. Rev. Respir. Dis. 136:586-591.

18. Dusser, D. J., D. B. Jacoby, T. D. Djokic, I. Rubinstein, D. B. Borson, and J. A. Nadel. 1989. Virus induces airway hyperresponsiveness to tachykinins: role of neutral endopeptidase. J. Appl. Physiol. 67:1504-1511.

19. Piedimonte, G., J. A. Nadel, E. Umeno, and D. M. McDonald. 1990. Sendai virus infection potentiates neurogenic inflammation in the rat trachea. $J$ Appl. Physiol. 68:754-760.

20. McDonald, D. M. 1988. Respiratory infections increase susceptibility to neurogenic inflammation in the rat trachea. Am. Rev. Respir. Dis. 137:14321440.

21. Schoeb, T. R., K. C. Kervin, and J. R. Lindsey. 1985. Exacerbation of murine respiratory mycoplasmosis in gnotobiotic $\mathrm{F} 344 / \mathrm{N}$ rats by Sendai virus infection. Vet. Pathol. 22:272-282.

22. Schoeb, T. R., and J. R. Lindsey. 1987. Exacerbation of murine respiratory mycoplasmosis by sialodacryoadenitis virus infection in gnotobiotic F344 rats. Vet. Pathol. 24:392-399.

23. Broderson, J. R., J. R. Lindsey, and J. E. Crawford, 1976. The role of environmental ammonia in respiratory mycoplasmosis of rats. Am. J. Pathol. 85:115-130.

24. Schoeb, T. R., M. K. Davidson, and J. R. Lindsey. 1982. Intracage ammonia promotes growth of Mycoplasma pulmonis in the respiratory tract of rats Infect. Immun. 38:212-217.

25. Saito, M., K. Nakayama, T. Muto, and M. Nakagawa. 1982. Effects of gaseous ammonia on Mycoplasma pulmonis infection in mice and rats. Exp. Anim. (Tokyo). 31:203-206.

26. Gamse, R., P. Holzer, and F. Lembeck. 1980. Decrease of substance P in primary afferent neurones and impairment of neurogenic plasma extravasation by capsaicin. Br. J. Pharmacol. 68:207-213.

27. Saria, A., J. M. Lundberg, G. Skofitsch, and F. Lembeck. 1983. Vascular protein leakage in various tissues induced by substance $P$, capsaicin, bradykinin serotonin, histamine and by antigen challenge. Naunyn-Schmiedeberg's Arch. Pharmacol. 324:212-218.

28. Lundberg, J. M., E. Brodin, X. Hua, and A. Saria. 1984. Vascular permeability changes and smooth muscle contraction in relation to capsaicin-sensitive substance $P$ afferents in the guinea pig. Acta Physiol. Scand. 120:217-227.

29. Saria, A., and J. M. Lundberg. 1983. Evans blue fluorescence: quantitative and morphological evaluation of vascular permeability in animal tissues. $J$. Neurosci. Methods. 8:41-49. 
30. Joris, I., U. DeGirolami, K. Wortham, and G. Majno. 1982. Vascular labelling with Monastral blue B. Stain Technol. 57:177-183.

31. Makara, G. B., L. Gyorgy, and J. Molnar. 1967. Circulatory and respiratory responses to capsaicin, 5-hydroxytryptamine and histamine in rats pretreated with capsaicin. Arch. Int. Pharmacodyn. 170:39-45.

32. Davidson, M. K., J. R. Lindsey, R. F. Parker, J. G. Tully, and G. H. Cassell. 1988. Differences in virulence for mice among strains of Mycoplasma pulmonis. Infect. Immun. 56:2156-2162.

33. Brokaw, J. J., and D. M. McDonald. 1988. The neurally-mediated increase in vascular permeability in the rat trachea: onset, duration and tachyphylaxis. Exp. Lung Res. 14:757-767.

34. Jancso-Gabor, A. J. Szolcsanyi, and N. Jancso. 1967. A simple method for measuring the amount of azovan blue exuded into the skin in response to an inflammatory stimulus. J. Pharm. Pharmacol. 19:486-487.

35. McDonald, D. M., R. A. Mitchell, G. Gabella, and A. Haskell. 1988. Neurogenic inflammation in the rat trachea. II. Identity and distribution of nerves mediating the increase in vascular permeability. J. Neurocytol. 17:605628.

36. Baljet, B., and J. Drukker. 1975. An acetylcholinesterase method for in toto staining of peripheral nerves. Stain Technol. 50:31-36.

37. Baker, D. G., D. M. McDonald, C. B. Basbaum, and R. A. Mitchell. 1986 The architecture of nerves and ganglia of the ferret trachea as revealed by acetylcholinesterase histochemistry. J. Comp. Neurol. 246:513-526.

38. Higgy, K. E., G. F. Burns, and F. G. J. Hayhoe. 1977. Discrimination of B T and null lymphocytes by esterase cytochemistry. Scand. J. Haematol. 18:437448.

39. Zar, J. H. 1974. Biostatistical Analysis. Prentice-Hall, Inc. Englewood Cliffs, NJ. 620 pp.

40. Carthew, P., and S. Sparrow. 1980. Sendai virus in nude and germ-free rats. Res. Vet. Sci. 29:289-292.
41. Castleman, W. L. 1983. Respiratory tract lesions in weanling outbred rats infected with Sendai virus. Am. J. Vet. Res. 44:1024-1031.

42. McDonald, D. M. 1990. The ultrastructure and permeability of tracheobronchial blood vessels in health and disease. Eur. J. Respir. 3(Suppl.):572s-585s.

43. Matsas, R., A. J. Kenny, and A. J. Turner. 1984. The metabolism of neuropeptides; the hydrolysis of peptides, including enkephalins, tachykinins and their analogues, by endopeptidase-24.11. Biochem. J. 223:433-440.

44. Mumford, R. A., P. A. Pierzchala, A. W. Strauss, and M. Zimmerman.

1981. Purification of a membrane-bound metalloendopeptidase from porcine kidney that degrades peptide hormones. Proc. Natl. Acad. Sci. USA. 78:66236627.

45. Skidgel, R. A., A. Engelbrecht, A. R. Johnson, and E. G. Erdos. 1984. Hydrolysis of substance $P$ and neurotensin by converting enzyme and neutral endoproteinase. Peptides (NY). 5:769-776.

46. Lindsey, J. R., H. J. Baker, R. G. Overcash, G. H. Cassell, and C. E. Hunt. 1971. Murine chronic respiratory disease. Am. J. Pathol. 64:675-716.

47. Cassell, G. H., W. A. Clyde, Jr., and J. K. Davis. 1985. Mycoplasmal respiratory infections. In The Mycoplasmas. Vol. IV. Mycoplasma Pathogenicity. S. Razin and M. F. Barile, editors. Academic Press, Inc., Orlando, FL. 65106.

48. Naot, Y., S. Davidson, and E. S. Lindenbaum. 1981. Mitogenicity and pathogenicity of Mycoplasma pulmonis in rats. I. Atypical interstitial pneumonia induced by mitogenic mycoplasmal membranes. J. Infect. Dis. 143:55-62.

49. Davis, J. K., R. B. Thorp, P. A. Maddox, M. B. Brown, and G. H. Cassell. 1982. Murine respiratory mycoplasmosis in F344 and LEW rats: evolution of lesions and lung lymphoid cell populations. Infect. Immun. 36:720-729.

50. Boushey, H. A., M. J. Holtzman, J. R. Sheller, and J. A. Nadel. 1980. Bronchial hyperreactivity. Am. Rev. Respir. Dis. 121:389-413.

51. Empey, D. W., L. A. Laitinen, L. Jacobs, W. M. Gold, and J. A. Nadel. 1976. Mechanisms of bronchial hyperreactivity in normal subjects after upper respiratory tract infection. Am. Rev. Respir. Dis. 113:131-139. 